\title{
The Protective Effect of Ligustilide in Osteoarthritis: An in Vitro and in Vivo Study
}

\author{
Xiaobin Lia,b Dengying Wu $\mathrm{W}^{\mathrm{a}, \mathrm{b}}$ Zhichao Hu $\mathrm{H}^{\mathrm{a}, \mathrm{b}}$ Jiangwei Xuan ${ }^{\mathrm{a}, \mathrm{b}}$ \\ Xiaoxia Ding c Gang Zhenga,b Zhenhua Feng ${ }^{a, b}$ Wenfei Nia,b \\ Aimin $W^{a, b}$
}

aDepartment of Orthopaedics, The Second Affiliated Hospital and Yuying Children's Hospital of Wenzhou Medical University, Wenzhou, 'bZhejiang Provincial Key Laboratory of Orthpaedics, Wenzhou, 'Department of Chemoradiation Oncology, The First Affiliated Hospital of Wenzhou Medical University, Wenzhou, China

\section{Key Words}

Ligustilide • Osteoarthritis • Chondrocytes $•$ PIK3/NF-KB $・$ IL-1 $\beta$ Inflammation

\begin{abstract}
Background/Aims: Osteoarthritis is a degenerative joint disease characterized by cartilage degeneration and a chondrocyte inflammatory response that induces an inflammatory environment closely linked to extracellular matrix (ECM) degradation. Ligustilide (LIG) is a major component of the herb Radix Angelicae Sinensis, with demonstrated anti-inflammatory effects. To confirm whether LIG has an equally inhibitory effect on inflammation in human osteoarthritis chondrocytes, we performed in vivo and in vitro experiments to validate the above conjectures and determine the relevant mechanisms. Methods: Quantitative realtime PCR and western blotting were performed to evaluate the expression of MMP-3, MMP-13, ADAMTS-5, iNOS, and COX-2 at both gene and protein levels. An enzyme-linked immunosorbent assay was used to evaluate the levels of other inflammatory factors (PGE2, TNF- $\alpha$, and IL-6). The PI3K/AKT and nuclear factor kappa B (NF-KB) signaling pathways were also analyzed by western blotting, whereas immunofluorescence was used to assess the expression of collagen II and aggrecan. The in vitro effect of LIG was evaluated by intraperitoneal injection into a mouse osteoarthritis model induced by destabilization of the medial meniscus. Results: LIG lowered the phosphorylation levels of $\mathrm{p} 65, \mathrm{IKB} \alpha$, and IKK $\alpha / \beta$ and suppressed the IL-1 $\beta$ induced expression of MMP-3, ADAMTS-5, iNOS, and COX-2 and the inflammatory factors PGE2, TNF- $\alpha$, and IL-6. LIG markedly decreased IL-1 $\beta$-induced degradation of collagen II and aggrecan. In vivo results showed that LIG-treated mouse cartilage showed less damage than the control group; the Osteoarthritis Research Society International (OARSI) score was also lower. LIG further reduced the thickness of the subchondral bone plate and alleviated the synovitis.
\end{abstract}

\begin{tabular}{ll}
\hline Wenfei Ni & Dept. of Orthopaedic Surgery, The $2^{\text {nd }}$ Affiliated Hospital and Yuying Children's Hospital of Wenzhou Med. Univ. \\
and Aimin Wu & 109\# Xueyuan Xi Road, Wenzhou, 325027 (China) \\
& Fax 8657788002823, E-Mail wenfeini@yeah.net; aiminwu@wmu.edu.cn
\end{tabular}


Conclusion: LIG may act as a promising therapeutic agent for osteoarthritis by attenuating $\mathrm{IL}-1 \beta$-induced inflammation in chondrocytes and ECM degradation via suppression of NF-KB activation by the PI3K/AKT pathway.

(C) 2018 The Author(s)

Published by S. Karger AG, Basel

\section{Introduction}

Osteoarthritis $(\mathrm{OA})$ is a degenerative joint disease characterized by cartilage degeneration. Cartilage is an avascular, aneural, and alymphatic matrix synthesized by chondrocytes and the extracellular matrix (ECM), which mainly consists of type II collagen and aggrecan [1]. Cartilage degeneration includes ECM degeneration and cartilage tissue destruction. Type II collagen is cleaved by matrix metalloproteinases (MMPs), whereas aggrecan is cleaved by "a disintegrin and metalloproteinase with thrombospondin motifs" (ADAMTS) enzymes, most probably ADAMTS5 [2]. Many MMPs are increased in OA. Furthermore, MMP-13 not only degrades aggrecan, but also preferentially digests type II collagen, resulting in the destabilization of the collagen network. MMP-3 can also digest aggrecan [3-5].

There is mounting evidence that the cartilage destruction in $\mathrm{OA}$ is the result of cartilage inflammation at the molecular level [6, 7]. Pro-inflammatory cytokines such as interleukin-1 beta (IL-1 $\beta$ ) and tumor necrosis factor alpha (TNF- $\alpha$ ) produced by activated synoviocytes, mononuclear cells, or articular cartilage itself are strongly linked to the pathophysiology of OA $[8,9]$. These factors serve to increase the catabolic activity of the chondrocyte, which results in the release of proteolytic enzymes, including ADAMTS and MMPs, which cause destruction of the ECM [10]. Among these cytokines, IL-1 $\beta$ exert its inflammatory effects by significantly increasing the secretion of inflammatory cytokines such as interleukin- 6 (IL6), inducible nitric oxide synthase (iNOS), cyclooxygenase 2 (COX2), and prostaglandin e2 (PGE2). PGE2 contributes to articular inflammation and destruction by enhancing the activation and production of MMPs and inhibiting the synthesis of anabolic macromolecules such as collagen and proteoglycan [8].

Studies aimed at unraveling the underlying molecular alterations induced by proinflammatory cytokines under chronic inflammatory conditions revealed that IL-1 $\beta$ activates a ubiquitous central transcription factor known as $\mathrm{NF}-\mathrm{\kappa B}$, which is a key regulator of gene expression $[11,12]$. In the inactive state, $\mathrm{NF}-\kappa \mathrm{B}$ is present in the cytoplasm as a heterotrimer complex consisting of two subunits and an additional inhibitory subunit, I $\mathrm{B} \alpha$. Of the five different subunits, p65/p50 is one of the most prevalent combinations [13]. Activation of the NF- $\kappa B$ pathway results in phosphorylation of $\mathrm{p} 65$ and $\mathrm{I} \kappa \mathrm{B} \alpha$ in the cytoplasm and ultimately the translocation of $\mathrm{p} 65$ from the cytoplasm to the nucleus [14]. The PI3K/AKT pathway, one of the most widely studied upstream signaling pathways of NF- $\kappa B$, is involved in both cellular and ECM alterations [15]. Currently, there are no effective target drugs for the treatment of $\mathrm{OA}$, and inhibition of these inflammatory mediators would be reasonable therapeutic targets for OA.

Ligustilide (LIG) is the main bioactive component of Danggui, which is the root of Angelica sinensis and one of the most popular traditional Chinese medicines [16]. Recent studies showed that LIG has an anti-inflammatory effect because it reduces the production of LPSinduced pro-inflammatory mediators (e.g., pro-inflammatory cytokines and inflammatory enzymes) in microglia and macrophages and of LPS-induced chemokines in astrocytes [1719]. LIG can inhibit the LPS-induced increase in inflammatory cytokines (TNF- $\alpha$, IL-1, and IL6) [20]. Additionally, LIG may help to protect PC12 cells against oxidative stress by activating hormetic pathways such as PI3K/AKT [21]. Moreover, the inhibitory effect of LIG on Prxinduced inflammation is probably associated with downregulation of TLR4/NF- $\kappa B$ signaling activation in macrophages [22]. However, the anti-inflammatory effects of LIG in OA have not been reported. Therefore, we investigated the anti-inflammatory effects of LIG and the underlying mechanism in IL-1 $\beta$-stimulated human chondrocytes in vitro and the protective role of LIG in mouse OA models in vivo. 


\section{Cellular Physiology Cell Physiol Biochem 2018;48:2583-2595 \begin{tabular}{ll|l} 
and Biochemistry Published online: 16 August, 2018 & $\begin{array}{l}\text { (c) } 2018 \text { The Author(s). Published by S. Karger AG, Basel } \\
\text { www.karger.com/cpb }\end{array}$
\end{tabular}}

\section{Materials and Methods}

\section{Chemicals and Reagents}

The ligustilide (purity> 98.5\%), recombinant human IL-1 $\beta$, collagenase type II, dimethylsulfoxide (DMSO)were obtained from Sigma Chemical Co. (St.Louis, MO, USA). The ligustilide was dissolved in DMSO as a $50 \mathrm{mM}$ stock solution and stored at $4{ }^{\circ} \mathrm{C}$. Further dilution was done in cell culture medium. Cell-Counting Kit-8 (CCK-8) was purchased from Dojindo (Kumamoto, Japan). Primary antibodies against $\beta$-actin was purchased from Sigma Chemical Co. (St. Louis, MO, USA). Primary antibodies against COX-2, iNOS, MMP-3, MMP-13, ADAMTS-5 and collagen-II were purchased from Abcam (Cambridge, MA, USA). Goat anti-rabbit and goat anti-mouse horseradish peroxidase conjugates were purchased from Bio $\backslash$ Rad Laboratories (Calif., USA). Fetal bovine serum (FBS), bovine serum albumin (BSA), Dulbecco's modified Eagle's medium (DMEM)/Ham's F12 medium and 0.25\% trypsin-ethylendiaminetetraacetic acid (trypsinEDTA) were purchased from Gibco (Life Technologies Corp. Carlsbad, Calif., USA). TRIzol reagent was purchased from Invitrogen (Carlsbad, Calif., USA). QuantiTect Reverse Transcription kit was purchased from Qiagen (Valencia, CA). ELISA kits of PGE2, TNF- $\alpha$ and IL-6 were purchased from R\&D systems (Minneapolis, MN, USA). Griess reagent was purchased from Beyotime Institute of Biotechnology (Shanghai, China).

\section{Primary human Chondrocyte Culture}

Articular cartilage sample collection was according to the terms of the Medical Ethical Committee of the Second Affiliated Hospital, Wenzhou Medical University and following the guidelines of the Declaration of Helsinki and Tokyo. OA human cartilage tissues were obtained from four OA patients (aged 53-65 years, two men and two women) who underwent total knee replacement surgery at the Second Affiliated Hospital of Wenzhou Medical University. The OA patients met the American College of Rheumatology (ACR) classification criteria for the diagnosis of osteoarthritis [23]. Full ethical consent was obtained from all patients. Cartilage was separated from underlying bone and connective tissues, and the obtained cartilage tissues were cut into $1 \times 1 \times 1 \mathrm{~mm} 3$ pieces and washed three times with PBS. Afterwards, the joint cartilage pieces were digested with $0.25 \%$ trypsin-EDTA solution. After removing $0.25 \%$ trypsin-EDTA, they were digested in $0.2 \%$ collagenase type II for $5 \mathrm{~h}$ at $37^{\circ} \mathrm{C}$ and then centrifuged at $1000 \mathrm{rpm}$ for $5 \mathrm{~min}$, and the supernatant was discarded. The inner cell mass was obtained and suspended in DMEM/F12 with $10 \%$ FBS and $1 \%$ antibiotic mixture (penicillin and streptomycin). Finally, cells were plated at a density of $1 \times 10^{\wedge} 5$ cells $/ \mathrm{ml}$ in 6-well plates and incubated in a humidified atmosphere of $5 \% \mathrm{CO} 2$ at $37{ }^{\circ} \mathrm{C}$. The media were changed every 2-3 days. Cells were passaged when at 80 to $90 \%$ confluence using $0.25 \%$ trypsin-EDTA solution. Only passages 1 to 3 were used in our study to avoid phenotype loss.

\section{Cell viability}

Cell viability was assessed using the Cell Counting Kit-8 (CCK8) assay. Human OA chondrocytes were cultured in 96-well plates at a density of $5 \times 10^{\wedge} 3$ cells per well for $24 \mathrm{~h}$. In brief, human OA chondrocytes were pretreated with or without different concentrations (5,25, 50, 100 and $250 \mu \mathrm{M}$ ) of LIG for $24 \mathrm{~h}$ and 48h. After that, $10 \mu \mathrm{L}$ CCK- 8 was added to each well and incubated at $37^{\circ} \mathrm{C}$ for $4 \mathrm{~h}$. The optical density was read at a wavelength of $450 \mathrm{~nm}$ with a microplate reader (Leica Microsystems, Germany).

\section{Griess Reaction and ELISAs}

The nitrite levels in the culture medium were assessed by Griess reaction.The levels of PGE2, TNF- $\alpha$ and IL-6 MMP-3, MMP-13 and ADAMTS-5 in the culture medium were evaluated using commercial ELISA kits according to the manufacturer's instructions (R\&D Systems, Minneapolis, MN). All assays were performed in duplicate.

\section{RNA isolation and $q R T-P C R$}

Total RNA was isolated from human OA chondrocytes by TRIzol reagent according to the manufacturer's instructions. Its concentration was determined spectrophotometrically at $260 \mathrm{~nm}$ (Thermo Scientific NanoDrop 2000). The A260/A280 ratio was calculated to verify quality and purity. First-strand cDNA was synthesized using $1 \mu \mathrm{g}$ of total RNA and the QuantiTect Reverse Transcription kit. Quantitative real-time PCR(qRT-PCR) was performed using CFX96 Real-Time PCR System (Bio-Rad Laboratories, California, USA), 


\section{Cellular Physiology Cell Physiol Biochem 2018;48:2583-2595 \begin{tabular}{l|l|l} 
and Biochemistry & Dublished onlIne: 16 August, 2018 & $\begin{array}{l}\text { (c) 2018 The Author(s). Published by S. Karger AG, Basel } \\
\text { www.karger.com/cpb }\end{array}$
\end{tabular}}

Li et al.: The Protective Effect of Ligustilide in Osteoarthritis

under the following conditions: $10 \mathrm{~min} 95^{\circ} \mathrm{C}$, followed by 40 cycles of $15 \mathrm{~s} 95{ }^{\circ} \mathrm{C}$ and 1 min $60{ }^{\circ} \mathrm{C}$. The reaction was performed in a total volume of $10 \mu \mathrm{L}$, containing $4.5 \mu \mathrm{L}$ diluted cDNA, $0.25 \mu \mathrm{L}$ forward primer, $0.25 \mu \mathrm{L}$ reverse primer and $5 \mu \mathrm{L}$ SYBR Green Master Mix. The level of target mRNA was normalized to the level of GAPDH and compared with control. Data were analyzed using $2^{-\triangle \Delta C T}$ method. Each gene analysis was performed in triplicate. Primer's sequences of the targeted genes were listed in Table 1.

\section{Western blotting}

The proteins were extracted from chondrocytes using RIPA lysis buffer. Lysates were sonicated on ice and centrifuged at $12,000 \mathrm{rpm}$ for $30 \mathrm{~min}$ at $4{ }^{\circ} \mathrm{C}$. The protein concentration of the supernatant was determined using the BCA protein assay kit. $40 \mu \mathrm{g}$ of total protein were resolved on 12\% SDS-PAGE and transferred to PVDF membranes. Membranes were incubated with blocking buffer $5 \%$ non-fat in TBS containing $0.1 \%$ Tween-20 for $2 \mathrm{~h}$ at room temperature and then probed with the primary antibodies against COX-2, iNOS, ADAMTS-5 ,MMP-3, MMP-13 ,p65, p-p65,IкB- $\alpha$, p-IкB- $\alpha$,PI3K(P110), PI3K(P85), AKT , p-AKT and $\beta$-actin(dilution 1:1000) overnight at $4{ }^{\circ} \mathrm{C}$. After washing three times with TBS containing $0.1 \%$ Tween-20 for $5 \mathrm{~min}$, the membranes were incubated with HRP-conjugated secondary antibodies (dilution 1:3000) for $2 \mathrm{~h}$. Finally membranes were detected by Enhanced Chemiluminescence (ECL) kit and quantified by the Quantity ONE (Bio-Rad, Hercules, CA, USA) software. $\beta$-actin was used as an internal control.

\section{Immunofluorescence microscopy}

Chondrocytes were seeded on 6-well plates on glass coverslips and incubated for $24 \mathrm{~h}$. For collagen II staining, the cellswere treated with $10 \mathrm{ng} / \mathrm{mlIL}-1 \beta$ orbeing co-treated with $10 \mathrm{ng} / \mathrm{ml} I \mathrm{~L}-1 \beta$ and $50 \mu \mathrm{MLIG}$ for 24 h in medium afterincubated with serum-starved medium overnights. For 65 staining, the duration of the IL-1 $\beta$ and LIG treatment was down to $2 \mathrm{~h}$. After treatments, glass coverslips with chondrocyte monolayers were rinsed three times in PBS. Then cells were fixed with 4\% paraformaldehyde for $15 \mathrm{~min}$ at room temperature and rinsed with PBS again. Cells and nuclear membranes were permeabilized with $0.1 \%$ Triton X-100 in for 5 min at room temperature. Later, cells were overlaid with 5\% protease-free BSA for $1 \mathrm{~h}$ at room temperature, rinsed with PBS and incubated with primary antibody against collagen-II(1:200) and p65 (1:200) at $4{ }^{\circ} \mathrm{C}$ overnight. After washing with PBS, cells were incubated with fluorescein-conjugated goat anti-rabbit IgG antibody (1:500) for $1 \mathrm{~h}$ at room temperature. Finally, cells were washed three times with PBS and mounted in medium containing DAPI (Invitrogen). Slides were viewed with a confocal laser scanning microscope (Leica Microsystems, Germany). Fluorescence intensity was measured using Image J software 2.1 (Bethesda, MD, USA).

\section{Mice OA models}

Ten-week-old C57BL/6 male wild-type (WT) mice were purchased from Animal Center of Chinese Academy of Sciences, Shanghai, China. The protocol for animal care and use conformed to the Guide for the Care and Use of Laboratory Animals of the National Institutes of Health and was approved by the Animal Care and Use Committee of Wenzhou Medical University. The experimental mice were subjected to surgically induced OA by destabilization of the medial meniscus (DMM) as previously described [24]. In brief, after anaesthesia with peritoneal injection of $4 \%$ chloral hydrate, the cranial attachment of the medial meniscus to the tibial plateau (medial meniscotibial ligament) of the right knee was transected with a microsurgical knife. The lateral meniscotibial ligament was identified and protected during the surgery. A sham operation, consisting of an arthrotomy without the transaction of medial meniscotibial ligament, was also performed in the right knee joint of mice in sham control group and sham LIG group.

\section{Experimental animal design}

The mice were randomly divided into three groups of 10 mice to establish a sham control group (sham), an osteoarthritis group (OA) and an osteoarthritis treated with LIG group (LIG). Mice

Table 1. Primer sequences used in qRT-PCR experiments

\begin{tabular}{|c|c|c|}
\hline Gene & Forward primer & Reverse primer \\
\hline COX-2 & 5'-GAGAGATGTATCCTCCCACAGTCA-3' & 5'-GACCAGGCACCAGACCAAAG-3' $^{\prime}$ \\
\hline iNOS & 5'-CCTTACGAGGCGAAGAAGGACAG-3' & 5'-CAGTTTGAGAGAGGAGGCTCCG-3' \\
\hline MMP-3 & 5'-CTGGCCTGCTGGCTCATGCTT-3' & 5'-GCAGGGTCCTTGGAGTGGTCA-3' \\
\hline MMP-13 & 5'-CCAGAACTTCCCAACCAT-3' & 5'-AСССТССАТАATGTCATACC- $3^{\prime}$ \\
\hline ADAMTS-5 & 5'-GCAGAACATCGACCAACTCTACTC-3' & $5^{\prime}$-CCAGCAATGCCCACCGAAC-3' \\
\hline Collagen-II & 5'-CTCAAGTCGCTGAACAACCA-3' & 5'-GTCTCCGCTCTTCCACTCTG-3' \\
\hline GAPDH & 5'-TCTCСTCTGACTTCAACAGCGAC-3' & 5'-CCCTGTTGCTGTAGCCAAATTC-3' \\
\hline
\end{tabular}




\section{Cellular Physiology Cell Physiol Biochem 2018;48:2583-2595

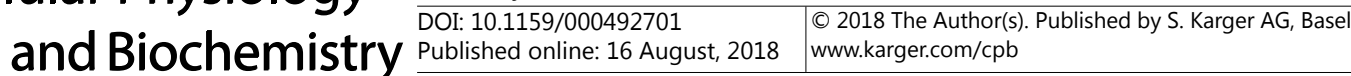

OA models were made by DMM surgery. LIG was dissolved in 2\% Lutrol F68 poloxamer 188 (BASF Corporation). Mice in sham and sham-LIG group were made by sham operation. Mice in sham-LIG group and LIG group received a gavage of LIG (40 mg/kg) daily for 8 weeks after surgery while mice in OA group received a gavage of vehicle $(2 \%$ Lutrol F68 poloxamer 188). Food and water were available. Mice were maintained under a constant temperature of $20 \pm 2 \mathrm{C}^{\circ}$, a relative humidity of $50 \% \pm 10 \%$, and a $12 \mathrm{~h}$ light/dark cycle. All animals were sacrificed at 8 weeks after surgery. Knee joint tissues were collected for further evaluation.

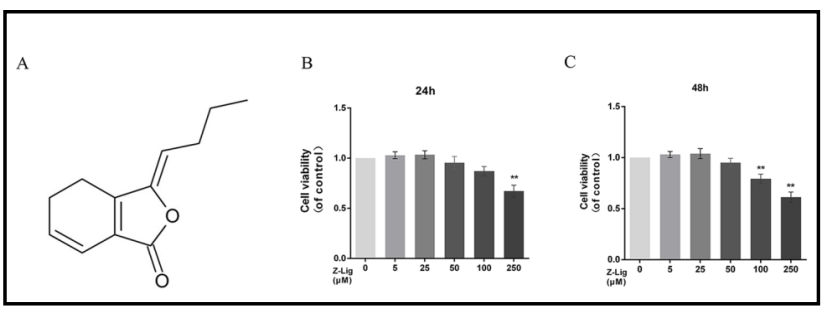

Fig. 1. Effects of Ligustilide on the cell viability of chondrocytes. Chemical structure of Ligustilide. (A). The cytotoxic effect of Ligustilide on chondrocytes was determined at various concentrations for 24 and 48 hours using a CCK8 assay. (B, C) The values presented are the means \pm S.D. of three independent experiments. ${ }^{*} \mathrm{P}<0.05,{ }^{* *} \mathrm{P}<0.01$ vs. control group, $\mathrm{n}=5$.

\section{Histological analysis}

Knee joint samples were fixed in $4 \%$ paraformaldehyde for $24 \mathrm{~h}$ at $4{ }^{\circ} \mathrm{C}$ and decalcified in $10 \%$ EDTA solution at $4{ }^{\circ} \mathrm{C}$ for two weeks. After that, the samples were dehydrated through an alcohol gradient, cleared, and embedded in paraffin blocks. Frontal serial sections ( $5 \mu \mathrm{m}$ thick) across entire joints were obtained and 10 slides per joint at every $50 \mu \mathrm{m}$ were selected and stained with Safranin-0/Fast Green and HematoxylinEosin staining to assess cartilage destruction. The stained sections were photographed digitally under a microscope. To determine the extent of cartilage degeneration, we used multiple separate scoring systems for articular cartilage destruction, synovitis and subchondral bone thickness. The destruction of articular cartilage was graded using the Osteoarthritis Research Society International (OARSI) scoring system for medial femoral condyle and medial tibial plateau [25]. Then we used a summed OARSI score (0-12) from medial femoral condyle and medial tibial plateau to evaluate the degree of articular cartilage destruction. The severity of synovitis was graded using a scoring system which was previously described [26]: Enlargement of the synovial lining cell layer on a scale of $0-3(0=1-2$ cells, $1=2-4$ cells, $2=4-9$ cells and $3=10$ or more cells) and density of cells in the synovial stroma on a scale of $0-3(0=$ normal cellularity, $1=$ slightly increased cellularity, 2 = moderately increased cellularity and 3 = greatly increased cellularity). We applied AxioVision software to measure the thickness of the medial subchondral bone plate according to SafraninO-stained sections.

\section{Statistical analysis}

All experiments were performed independently at least three times. Data are expressed as mean \pm standard deviation (SD). All analyses were performed using SPSS version 16.0 software. Statistical significance was assessed by one-way analysis of variance (ANOVA). $\mathrm{P}<0.05$ was considered statistically significant.

\section{Results}

\section{Effects of LIG on chondrocyte viability}

The cytotoxic effects of LIG on chondrocytes were determined at various concentrations $(5,25,50,100$, and $250 \mu \mathrm{M})$ for 24 and $48 \mathrm{~h}$ using the Cell Counting Kit-8 assay. As shown in Fig. 1, treatment with 250 or $100 \mu \mathrm{M}$ LIG significantly reduced cell viability at $24 \mathrm{~h}(\mathrm{P}<0.01$ vs. untreated cells) and $48 \mathrm{~h}(\mathrm{P}<0.05$ vs. untreated cells), respectively, indicating that cell viability was not affected by LIG at concentrations up to $50 \mu \mathrm{M}$ before $48 \mathrm{~h}$. Therefore, 5,25 , and $50 \mu \mathrm{M}$ LIG was used for subsequent experiments. 
Effects of LIG on inflammatory factor expression in IL-1 $\beta$-stimulated human chondrocytes Human chondrocytes were pretreated with various concentrations of LIG $(5,25$, and $50 \mu \mathrm{M})$ for $2 \mathrm{~h}$, followed by stimulation with or without IL-1 $\beta(10 \mathrm{ng} / \mathrm{ml})$ for $24 \mathrm{~h}$. iNOS and COX-2 levels were measured by both qRT-PCR and western blot analysis. As shown in Fig. 2, we found that IL-1 $\beta$ markedly increased the mRNA expression of iNOS and COX2 compared with the control group. However, LIG dose-dependently inhibited the mRNA expression of iNOS and COX-2 induced by IL-1 $\beta$. Consistent with the qRT-PCR results, the protein expression levels of iNOS and COX-2 induced by IL-1 $\beta$ were also significantly inhibited by LIG treatment in a dose-dependent manner. Moreover, LIG significantly inhibited PGE2, TNF- $\alpha$, and IL-6 generation at mRNA levels in a dosedependent manner (Fig. 3). Taken together, these results suggest that LIG inhibits the production of these inflammatory cytokines.

\section{Effects of LIG on ECM degradation in}

IL-1 $\beta$-treated human chondrocytes

The ECM mainly consists of aggrecan and type II collagen. As described above, type II collagen is cleaved by MMP (mainly MMP3 and MMP13), whereas aggrecan is cleaved by ADAMTS, most likely ADAMTS5. Western blot and qRT-PCR analysis showed that IL-1 $\beta$ significantly upregulated the expression of MMP3 and particularly MMP-13. However, LIG reversed this destructive effect in a dose-dependent manner. Similar results were obtained for ADAMTS- 5 (Fig. 4).

Then, we investigated the effect of LIG on IL-1 $\beta$-induced collagen II degradation in human $\mathrm{OA}$

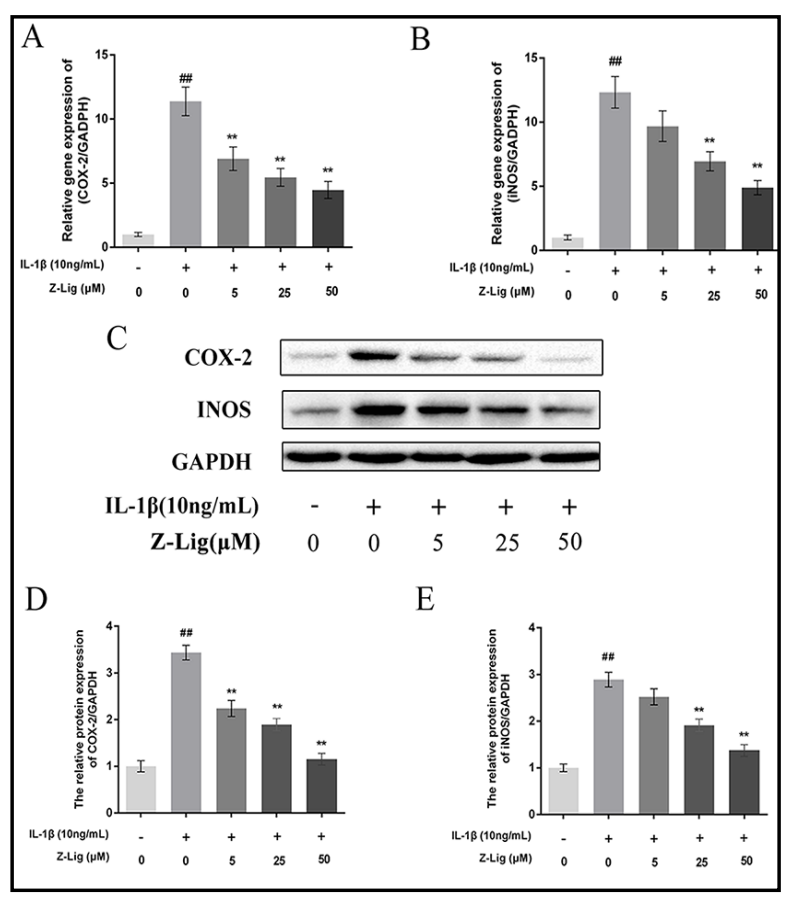

Fig. 2. Ligustilide inhibit inflammatory effect in chondrocyte. Human $\mathrm{OA}$ chondrocytes were pretreated for $2 \mathrm{~h}$ with various concentrations of Ligustilide (5, 25, 50 $\mu \mathrm{M}$ ) and then stimulated or not stimulated with IL-1 $1 \beta$ (10 $\mathrm{ng} / \mathrm{ml}$ ) for $24 \mathrm{~h}$. The mRNA expression levels of iNOs(A) and COX- 2(B) were assayed by qRT-PCR. The protein expressions of iNOS and COX-2 in chondrocytes treated as above were visualized by western blot (C), quantified in (D, E) .Significant differences among different groups are indicated as \#\# $\mathrm{P}<0.01$, vs control group; ${ }^{* *} \mathrm{P}<0.01$, vs IL$1 \beta$ alone treatment group, $\mathrm{n}=5$.

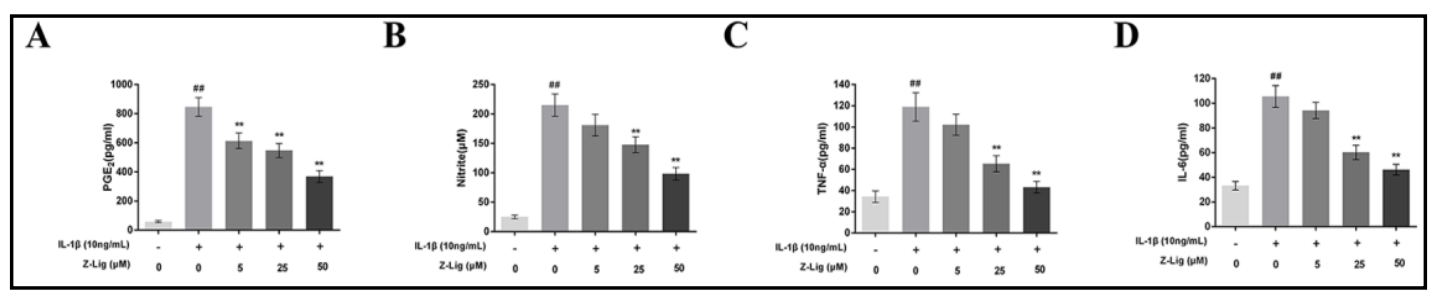

Fig. 3. Ligustilide inhibit inflammatory effect in human OA chondrocytes. Human OA chondrocytes were pretreated for $2 \mathrm{~h}$ with various concentrations of ligustilide $(5,25,50 \mu \mathrm{M})$ and then stimulated or not stimulated with IL-1 $\beta$ (10 ng/ml) for $24 \mathrm{~h}$. The nitrite levels in the culture medium were assessed by Griess reaction(B). The levels of PGE2, TNF- $\alpha$ and IL- 6 were determined using ELISA (A,C,D). The data in the figures represent the averages \pm S.D. Significant differences among different groups are indicated as \#\#P<0.01, vs control group; ${ }^{* *} \mathrm{P}<0.01$, vs IL- $1 \beta$ alone treatment group, $\mathrm{n}=5$.

\section{KARGER}


chondrocytes. Chondrocytes were pretreated with various concentrations of $\operatorname{LIG}(5,25$, and $50 \mu \mathrm{M}$ ) for $2 \mathrm{~h}$, followed by stimulation with or without IL-1 $\beta(10 \mathrm{ng} / \mathrm{ml})$ for $24 \mathrm{~h}$. The mRNA expression of collagen II was determined by qRT-PCR, and the protein expression of collagen II was detected by immunofluorescence. As shown in Fig. 5B, chondrocytes showed a clear downregulation of the mRNA expression of collagen II after IL-1 $\beta$ stimulation. Otherwise, LIG clearly inhibited the mRNA downregulation of collagen II. Moreover, the immunofluorescence results suggested that LIG signaling suppressed the protein degradation of collagen II, which is consistent with the results of qRT-PCR (Fig. 5A and C).

\section{Effects of IL-1 $\beta$ on the levels} of phosphorylated IKK/ I $\mathrm{K} \alpha \alpha / p 65$

To further reveal the mechanism, the phosphorylation levels of $\mathrm{p} 65$,

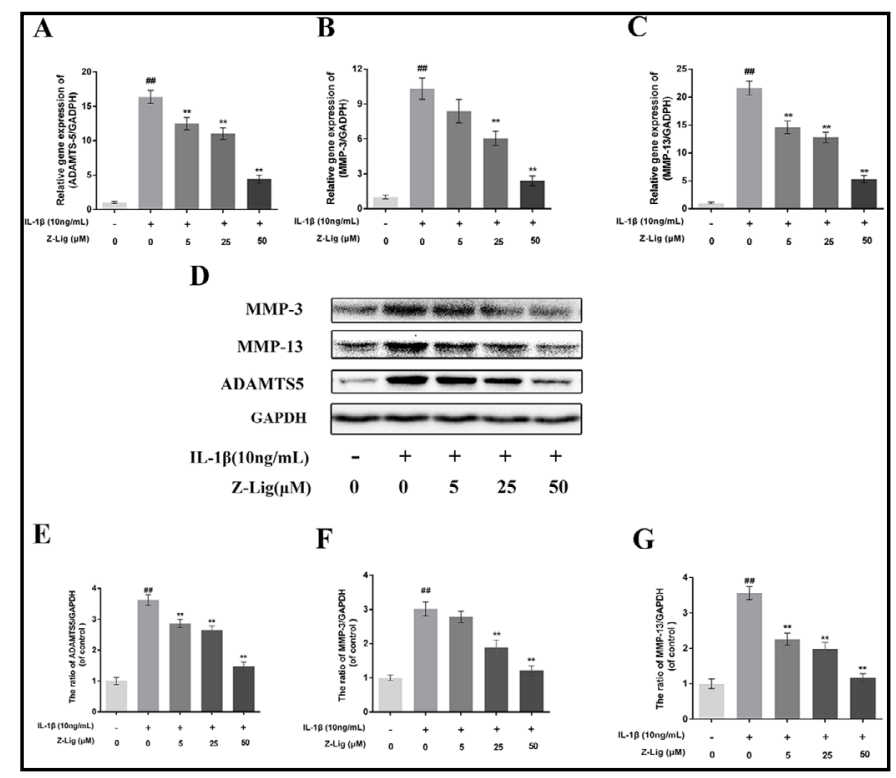

Fig. 4. Effect of Ligustilide on IL-1 $\beta$-inducedADAMTS-5, MMP-3 and MMP-13 expression in human OA chondrocytes. Human OA chondrocytes were pretreated for $2 \mathrm{~h}$ with various concentrations of Ligustilide $(5,25,50 \mu \mathrm{M})$ and then stimulated or not stimulated with IL-1 $\beta$ (10 ng/ml) for $24 \mathrm{~h}$. The mRNA expression levels of ADAMTS-5 (A) , MMP-3 (B) and MMP-13 (C) were assayed by qRT-PCR. The protein expression levels ofADAMTS-5, MMP-3 and MMP-13 were determined by Western blot and quantification analysis (D-G). The data in the figures represent the averages \pm S.D. Significant differences among different groups are indicated as \#\# $\mathrm{P}<0.01$, vs control group; ${ }^{* *} \mathrm{P}<0.01$, vs IL- $1 \beta$ alone treatment group, $\mathrm{n}=5$.

$\mathrm{I} \kappa \mathrm{B} \alpha$, and $\mathrm{IKK} \alpha / \beta$ in IL- $1 \beta$ -

stimulated chondrocytes were assessed by western blot after $2 \mathrm{~h}$. Subsequent analysis revealed that IL-1 $\beta$ markedly induced the phosphorylation of IKK $\alpha / \beta, \operatorname{I\kappa B} \alpha$, and NF- $\kappa B$ p65 (Fig. 6A and B).

\section{Effects of LIG on IL-1 $\beta$-induced $N F-\kappa B$ activation}

To examine the effects of LIG on NF- $\mathrm{BB}$ pathway activation, the phosphorylation levels of $\mathrm{p} 65$, I $\mathrm{KB} \alpha$, and IKK $\alpha / \beta$ in IL-1 $\beta$-stimulated chondrocytes were assessed by western blot at 2 h. IL-1 $\beta$ markedly induced the phosphorylation of IKK $\alpha / \beta$ and IKB $\alpha$, significantly so at $50 \mu \mathrm{M}$ (Fig. 7). Indirect immunofluorescence staining of p65 revealed the translocation of p65 from the cytoplasm to the nucleus in chondrocytes in response to NF- $\kappa B$ activation by IL-1 $\beta$. The chondrocytes were divided into three groups: (1) control group; (2) IL-1 $\beta$-stimulated group; and (3) IL-1 $\beta$ plus LIG treatment group. In the control group, most p65 protein was located in the cytoplasm. Upon IL-1 $\beta$ stimulation, p65-positive proteins were stained intensively in the nucleus of chondrocytes, leaving the cytoplasm unstained, indicating nuclear translocation of the NF- $\kappa B$ subunit. However, pretreatment with LIG inhibited the translocation of p65 subunits to the nucleus (Fig. 6C). These immunomorphological findings suggest an inhibitory effect of LIG on the IL-1 $\beta$-induced p65 nuclear dislocation in chondrocytes and are consistent with the inhibition of the NF- $\mathrm{BB}$ pathway observed by western blot. 
Fig. 5. Ligustilide inhibit extracellular matrix reduction from IL-1 $\beta$ induced in human OA chondrocytes. Human OA chondrocytes were pretreated for $2 \mathrm{~h}$ with ligustilide $(5,25$, $50 \mu \mathrm{M})$ and then stimulated or not stimulated with IL-1 $\beta$ (10 $\mathrm{ng} / \mathrm{ml}$ ) for $24 \mathrm{~h}$. The mRNA expression levels of collagenII (B) were assayed by qRTPCR. The representative collagen II (A) were detected by the immunofluorescence combined with DAPI staining

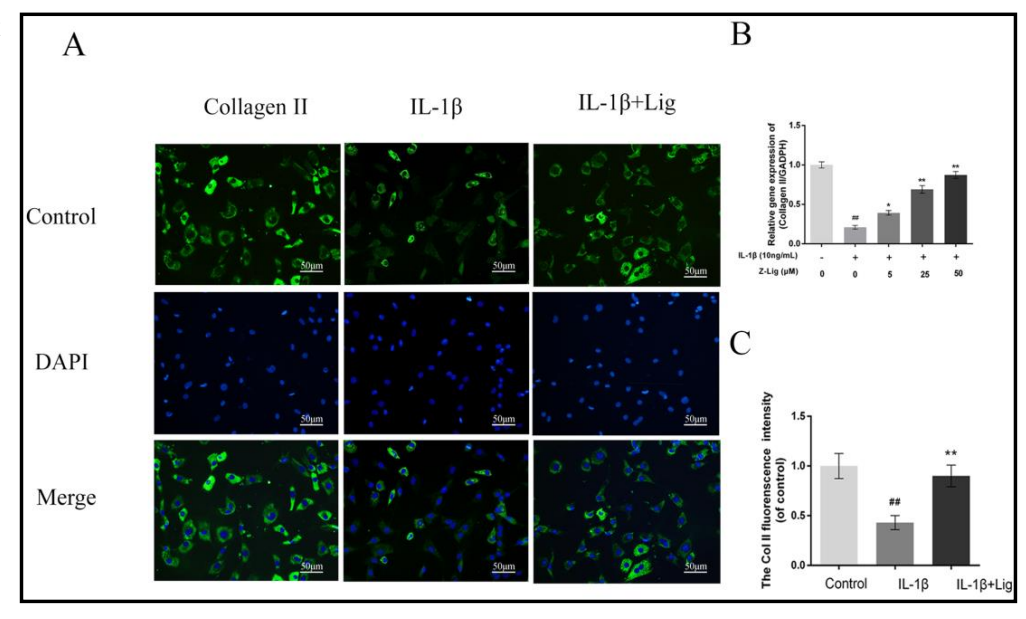
for nuclei. The fluorescence intensity of Col II (C) were analysed by image J. The data in the figures represent the averages \pm S.D. Significant differences among different groups are indicated as $\# \# \mathrm{P}<0.01$, vs control group; ${ }^{* *} \mathrm{P}<0.01$, vs IL-1 $\beta$ alone treatment group, $\mathrm{n}=5$.

Fig. 6. Effect of ligustilide on IL-1 $\beta$-induced NF- $\kappa B$ activation in human $\mathrm{OA}$ chondrocytes. Chondrocytes were pretreated with ligustilide $(5,25,50 \mu \mathrm{M})$ for $2 \mathrm{~h}$, followed by stimulation with or without IL-1 $\beta$ (10 $\mathrm{ng} / \mathrm{ml}$ ) for $1 \mathrm{~h}$. The protein expression of $\mathrm{I} \kappa \mathrm{B}, \mathrm{p}-\mathrm{I} \kappa \mathrm{B}, \mathrm{p} 65$ and p-p65 were determined by Western blot and quantification analysis(A,B). The nuclei translocation of p65 was detected by the immunofluorescence combined with DAPI staining for nuclei (original

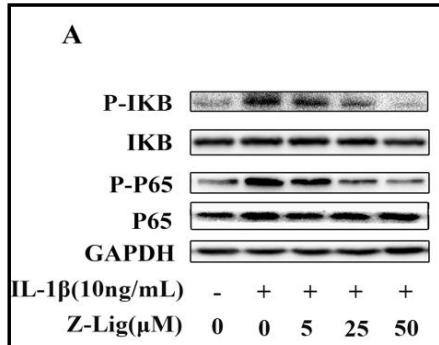

B

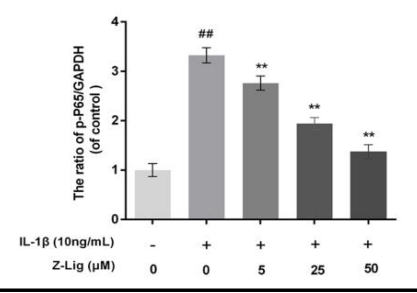

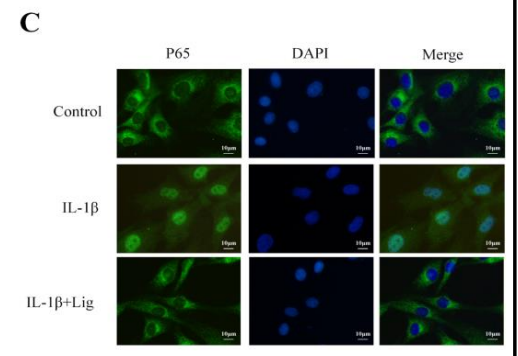

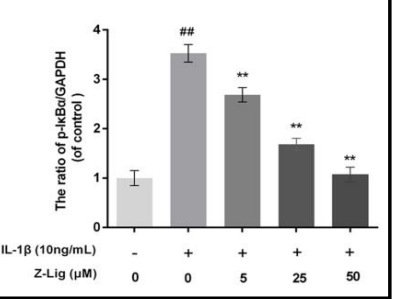
magnification $\times 400$, scale bar: $10 \mu \mathrm{m})(\mathrm{C})$. The data in the figures represent the averages \pm S.D. Significant differences among different groups are indicated as \#\# $\mathrm{P}<0.01$, vs control group; ${ }^{* *} \mathrm{P}<0.01$, vs IL-1 $\beta$ alone treatment group, $\mathrm{n}=5$.

\section{LIG ameliorates OA development in a mouse model involving destabilization of the medial meniscus}

To investigate the protective effects of LIG on OA development in vivo, a surgically induced mouse model involving destabilization of the medial meniscus (DMM) was established, followed by intraperitoneal injection of $40 \mathrm{mg} / \mathrm{kg} \mathrm{LIG}$ dissolved in $2 \%$ Lutrol F68 poloxamer 188 once daily for 8 weeks. Histological analysis of OA was performed using safranin 0 staining for cartilage and synovitis. Osteoarthritis Research Society International (OARSI) scores and synovitis scores were used for quantitative analysis. As revealed by the safranin 0 staining (Fig. 8A), the cartilage surface was smooth and showed positive red staining in the sham control group. The OA group showed cartilage erosion, apparent hypocellularity, and massive proteoglycan loss compared with the sham control group. However, the LIG 
group exhibited less proteoglycan loss compared with the OA group. Consistent with the safranin 0 staining, the OARSI scores (Fig. 8B) of the OA group were markedly higher than those of the sham control. In contrast, the LIG group displayed lower OARSI scores than the OA group. In addition, synovial thickening and hypercellularity was present in the OA group, whereas LIG treatment alleviated the synovitis compared with the OA group (Fig. 8C). Together, these results indicate that LIG protects against $\mathrm{OA}$ development in vivo by inhibiting the loss of proteoglycan, cartilage calcification, and synovitis.

\section{Discussion}

Drugs currently used for $\mathrm{OA}$, including non-steroidal antiinflammatory drugs and steroids, act against the pain and joint inflammation but fail to prevent disease progression and often cause many adverse effects [27, 28], which suggests that these drugs are not ideal choices for the treatment of OA. Thus, there is an urgent need to identify safe and effective agents that can slow the progression of OA.

LIG, a quinone extracted from the roots of medicinal herbs of the Plumbago genus, has anti-inflammatory effects. Here, we found that LIG significantly inhibited the IL-1 $\beta$-induced inflammatory response in chondrocytes. Furthermore, several other in vitro and in vivo studies have confirmed that the inflammatory environment plays a negative role in the stability of the chondrocyte phenotype and hemostasis of the ECM, which aggravates cartilage destruction and promotes OA progression [29-31]. Thus, we further investigated whether LIG can reverse these inflammation-induced conditions and explored the potential molecular mechanisms involved.

The inflammatory mediator PGE2 plays a crucial role in the pathogenesis of OA[32]. Previous reports showed that inhibition of the production of inflammatory mediators such

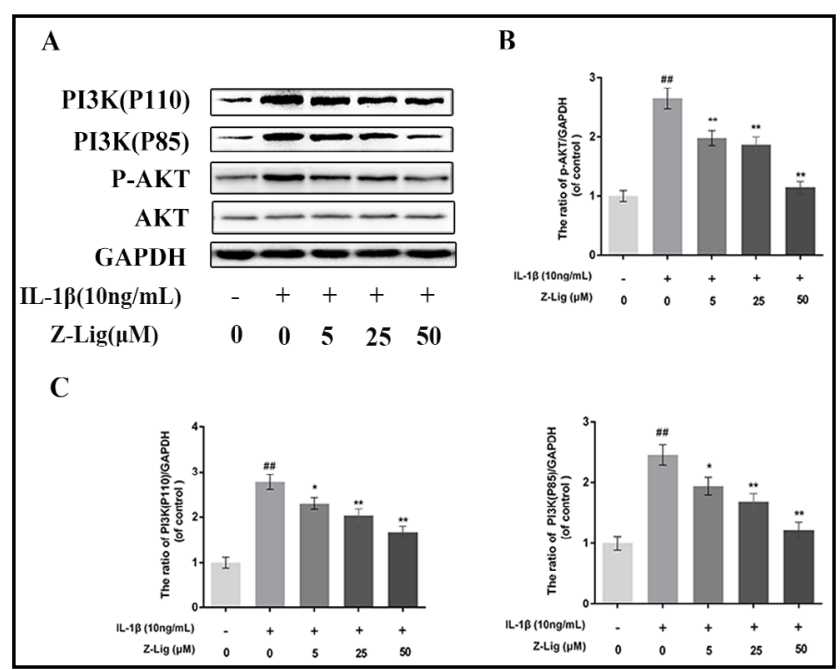

Fig. 7. Effect of ligustilide on IL-1 $\beta$-induced PI3K/AKT phosphorylation in human OA Chondrocytes. Chondrocytes were pretreated with ligustilide $(5,25,50 \mu \mathrm{M})$ for $2 \mathrm{~h}$, followed by stimulation with or without IL-1 $\beta(10 \mathrm{ng} / \mathrm{ml})$ for $1 \mathrm{~h}$. The protein expression levels of PI3K(P110), PI3K(P85), AKT and p-AKT were determined by Western blot and quantification analysis (A-C). The data in the figures represent the averages \pm S.D. Significant differences among different groups are indicated as $\# \# \mathrm{P}<0.01$, vs control group; ${ }^{* *} \mathrm{P}<0.01$, vs IL- $1 \beta$ alone treatment group, $\mathrm{n}=5$.

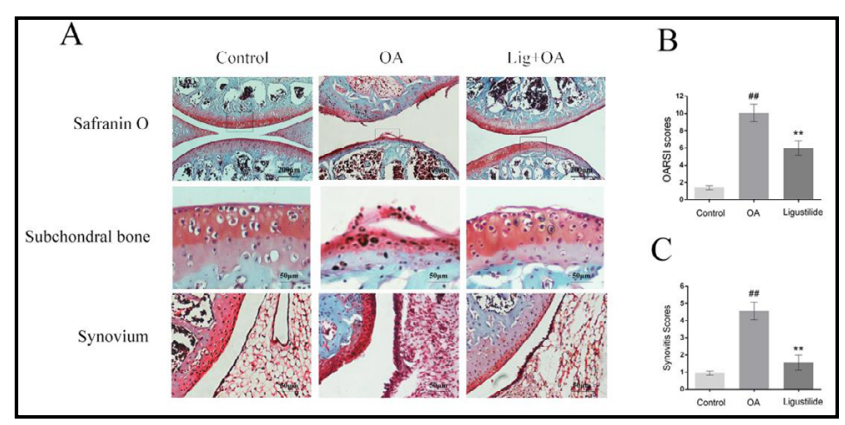

Fig. 8. Ligustilide ameliorates $\mathrm{OA}$ development in mouse DMM model in vivo. Representative S-O staining of cartilage and synovitis from different experimental groups at 8 weeks post-surgery(A) (original magnification $\times 100$ or $\times 400$, scale bar: $200 \mu \mathrm{m}$ or $50 \mu \mathrm{m})$. Diagrams showed the OARIS socres of cartilage (B). Diagrams showed the scores of synovitis (C). The data in the figures represent the averages \pm S.D. Significant differences among different groups are indicated as $\# \# \mathrm{P}<0.01$, vs sham group; ${ }^{* *} \mathrm{P}<0.01$, vs DMM group, $\mathrm{n}=10$. 
as PGE2 could slow down OA progression [33]. PGE2, a principal mediator of inflammation, is converted from endogenous arachidonic acid induced by IL- $1 \beta$ via COX- 2 catalytic reactions and is associated with cartilage destruction due to its powerful activation for MMPs and other inflammatory mediators [34,35]. All of these factors, as well as TNF- $\alpha$ and IL-6, are important inflammatory cytokines in OA development [36]. In this study, we found that overproduction of PGE2, TNF- $\alpha$, and IL- 6 after IL- $1 \beta$ stimulation is inhibited by LIG at the gene level, whereas COX-2 and iNOS are inhibited at both the gene and protein levels. These results are consistent with those from Yang et al., whose research revealed that LIG inhibits LPS-induced inflammatory activation in RAW264.7 macrophages [37]. Therefore, we surmised that the anti-inflammatory effects of LIG may be associated with inhibition of TNF- $\alpha$ and IL- 6 expression, as well as decreased production of PGE 2, via targeting of iNOS and COX-2.

As described above, the ECM consists of aggrecan and type II collagen, which can provide tensile strength and shock absorption under mechanical damage [38]. Inhibition of the degradation of collagen II and aggrecan may have positive effects on OA treatment. Type II collagen is cleaved by MMPs, whereas aggrecan is cleaved by ADAMTS[39-41]. In our study, in the presence of IL- $\beta$, LIG not only promoted the synthesis of type II collagen and aggrecan, but also inhibited the catabolism of ECM components by downregulating MMPs and ADAMTS-5, which helped to maintain ECM homeostasis.

To elucidate the mechanism by which LIG unites anti-inflammation and anti-catabolism in the ECM in chondrocytes, we further explored the cross-talk between the PI3K/AKT and $\mathrm{NF}-\kappa \mathrm{B}$ signaling pathways. NF- $\kappa \mathrm{B}$ is a ubiquitously expressed transcription factor involved in the regulation of inflammatory mediators associated with $\mathrm{OA}[42,43]$. According to previous studies [44], IL-1 $\beta$ stimulation triggers the phosphorylation of the catalytic subunits of IKK (IKK $\alpha$ and IKK $\beta$ ), as well as the binding protein of $\mathrm{p} 65$ (IKB $\alpha$ ), which consequently frees p65 and translocates it from the cytosol to the nucleus and leads to the production of catabolic enzymes, cytokines, and inflammatory mediators. Additionally, LIG inhibits inflammation in macrophages via NF- $\kappa B$ inhibition. Our data reveal that LIG inhibits IL-1 $\beta$-induced inflammation and ECM degradation by suppressing NF- $\kappa B$ signaling in chondrocytes.

Several upstream signaling molecules, such as STAT3, ERK1/2, TRAF6, IRAK1, and PI3K/ AKT, have been reported to be involved in IL-1 $\beta$-induced inflammation in chondrocytes. The intracellular messengers PI3K/AKT are one of the best-studied upstream signaling pathways [15]. The pathway regulates a cascade of changes through a variety of target proteins, such as mechanistic target of rapamycin (mTOR), NF- $\kappa B$, glycogen synthase kinase 3 beta (GSK$3 \beta$ ), and p53, all of which are involved in the OA process. Therefore, we further investigated the correlation between NF- $\mathrm{KB}$ and PI3K/AKT signaling during LIG treatment with respect to $\mathrm{OA}$. In the current study, IL-1 $\beta$ stimulation markedly upregulated the protein levels of the catalytic subunit (PI3K-p110) and the regulatory subunit (PI3K-p85) of PI3K, which catalyze the production of PIP3 and leads to the phosphorylation of AKT and subsequent activation of NF- $\kappa B$. Our data revealed that LIG blocks IL-1 $\beta$-induced AKT activation via inhibition of PI3K-p110 and PI3K-p85, which further targets the downstream NF- $\kappa B$ molecules. Thus, the results from previous studies along with ours indicate that the anti-inflammatory effects of LIG may be closely related to the inhibition of NF- $\kappa B$ activation via the PI3K/AKT pathway.

$\mathrm{DMM}$ is a reliable and effective method to establish an animal $\mathrm{OA}$ model for in vivo analysis. Thus, in this study, mouse OA models induced by DMM were used to examine the protective effects of LIG in vivo. Treatment with LIG dramatically reduced the OARSI scores as well as the severity scores of synovitis in our mouse OA model.

In this study, we found for the first time that LIG significantly inhibits the IL-1 $\beta$-induced inflammatory response in chondrocytes, including the expression of PGE2, iNOS, COX-2, MMP-3, MMP-13, and ADAMTS-5, and decreases the degradation of aggrecan and collagen II in human OA chondrocytes via the PI3K/AKT pathway. Furthermore, our results showed

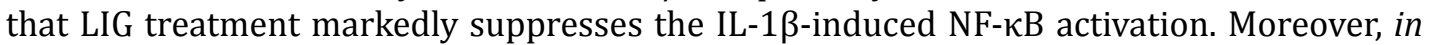
vivo, LIG treatment clearly prevented the development of OA in mouse OA models. Therefore, LIG may one day serve as an effective chemotherapeutic agent for the treatment of OA. 


\section{Cellular Physiology Cell Physiol Biochem 2018;48:2583-2595 \begin{tabular}{ll|l} 
and Biochemistry Published onlIne: 16 August, 2018 & $\begin{array}{l}\text { (c) } 2018 \text { The Author(s). Published by S. Karger AG, Basel } \\
\text { www.karger.com/cpb }\end{array}$ \\
\hline
\end{tabular}}

\section{Acknowledgements}

The authors thank all the staff in the Laboratory of Orthopaedic Research Institute and Scientific Research Center of Second Affiliated Hospital of Wenzhou Medical University. This study was supported by the Zhejiang Provincial Natural Science Foundation of China (Grant No. Y17H060051).

\section{Disclosure Statement}

The authors declare no conflicts of interest.

\section{References}

1 Aigner T, Mckenna L: Molecular pathology and pathobiology of osteoarthritic cartilage. Cell Mol Life Sci 2002;59:5-18.

-2 Stanton H, Rogerson FM, East CJ, Golub SB, Lawlor KE, Meeker CT, Little CB, Last K, Farmer PJ, Campbell IK: ADAMTS5 is the major aggrecanase in mouse cartilage in vivo and in vitro. Nature 2005;434:648-652.

3 Boileau C, Pelletier JP, Tardif G, Fahmi H, Laufer S, Lavigne M, Martelpelletier J: The regulation of human MMP-13 by licofelone, an inhibitor of cyclo-oxygenases and 5-lipoxygenase, in human osteoarthritic chondrocytes is mediated by the inhibition of the p38 MAP kinase signalling pathway. Ann Rheum Dis 2005;64:891-898.

-4 Martel-Pelletier J, Welsch DJ, Jean-Pierre Pelletier M: Metalloproteases and inhibitors in arthritic diseases. Best Pract Res Clin Rheumatol 2001;15:805-829.

-5 Yuan Y, Tan H, Dai P: Krüppel-Like Factor 2 Regulates Degradation of Type II Collagen by Suppressing the Expression of Matrix Metalloproteinase (MMP)-13. Cell Physiol Biochem 2017;42:2159-2168.

-6 Pelletier JP, Martel-Pelletier J, Abramson SB: Osteoarthritis, an inflammatory disease: potential implication for the selection of new therapeutic targets. Arthritis Rheumatol 2001;44:1237-1247.

7 Chen S, Zhang L, Xu R, Ti Y, Zhao Y, Zhou L, Zhao J: TheBDKRB2 + 9/-9 Polymorphisms Influence ProInflammatory Cytokine Levels in Knee Osteoarthritis by Altering TLR-2 Expression: Clinical and in vitro Studies. Cell Physiol Biochem 2016;38:1245.

8 Kapoor M, Martel-Pelletier J, Lajeunesse D, Pelletier JP, Fahmi H: Role of proinflammatory cytokines in the pathophysiology of osteoarthritis. Nat Rev Rheumatol 2014;7:33-42.

-9 Konttinen YT, Sillat T, Barreto G, Ainola M, Nordström DCE: Editorial: Osteoarthritis as an autoinflammatory disease caused by chondrocyte-mediated inflammatory responses. Arthritis Rheumatol 2012;64:613-616.

-10 Loeser RF: Molecular mechanisms of cartilage destruction: mechanics, inflammatory mediators, and aging collide. Arthritis Rheumatol 2006;54:1357-1360.

-11 Largo R, Alvarez SMOI, Calvo E, Sanchez PO, Egido J, Herrero BG: Glucosamine inhibits IL-1beta-induced NFkappaB activation in human osteoarthritic chondrocytes. Osteoarthritis Cartilage 2003;11:290.

$\checkmark 12$ Barnes PJ, Karin M: Nuclear factor-kappaB: a pivotal transcription factor in chronic inflammatory diseases. N Engl J Med 1997;336:1066-1071.

13 Kumar A, Takada Y, Boriek AM, Aggarwal BB: Nuclear factor-kappaB: its role in health and disease. J Mol Med (Berl) 2004;82:434-448.

14 Sizemore N, Lerner N, Dombrowski N, Sakurai H, Stark GR: Distinct roles of the Ikappa B kinase alpha and beta subunits in liberating nuclear factor kappa B (NF-kappa B) from Ikappa B and in phosphorylating the p65 subunit of NF-kappa B. J Biol Chem 2002;277:3863.

15 Chen J, Crawford R, Xiao Y: Vertical inhibition of the PI3K/Akt/mTOR pathway for the treatment of osteoarthritis. J Cell Biochem 2013;114:245.

-16 Zhao KJ, Dong TT, Tu PF, Song ZH, Lo CK, Tsim KW: Molecular genetic and chemical assessment of radix Angelica (Danggui) in China. J Agric Food Chem 2003;51:2576-2583. 


\section{Cellular Physiology Cell Physiol Biochem 2018;48:2583-2595 \begin{tabular}{l|l} 
and Biochemistry & DOI: 10.1159/000492701 \\
(c) 2018 The Author(s). Published by S. Karger AG, Basel \\
www.karger.com/cpb
\end{tabular}

17 Or TC, Yang CL, Law AH, Li JC, Lau AS: Isolation and identification of anti-inflammatory constituents from Ligusticum chuanxiong and their underlying mechanisms of action on microglia. Neuropharmacology 2011;60:823-831.

18 Su YW, Chiou WF, Chao SH, Lee MH, Chen CC, Tsai YC: Ligustilide prevents LPS-induced iNOS expression in RAW 264.7 macrophages by preventing ROS production and down-regulating the MAPK, NF- $\kappa$ B and AP-1 signaling pathways. Int Immunopharmacol 2011;11:1166-1172.

19 Zhao LX, Jiang BC, Wu XB, Cao DL, Gao YJ: Ligustilide attenuates inflammatory pain via inhibition of NFkBmediated chemokines production in spinal astrocytes. Eur J Neurosci 2014;39:1391-1402.

-20 Zhu MD, Zhao LX, Wang XT, Gao YJ, Zhang ZJ: Ligustilide inhibits microglia-mediated proinflammatory cytokines production and inflammatory pain. Brain Res Bull 2014;109:54-60.

-21 Qi H, Han Y, Rong J: Potential roles of PI3K/Akt and Nrf2-Keap1 pathways in regulating hormesis of Z-ligustilide in PC12 cells against oxygen and glucose deprivation. Neuropharmacology 2012;62:16591670.

22 Zhao LX, Du JR, Zhou HJ, Liu DL, Gu MX, Long FY: Differences in Proinflammatory Property of Six Subtypes of Peroxiredoxins and Anti-Inflammatory Effect of Ligustilide in Macrophages. PLoS One 2016;11:e0164586.

23 Palmieri B, Lodi D, Capone S: Osteoarthritis and degenerative joint disease: local treatment options update. Acta Biomed 2010;81:94-100.

24 Vasheghani F, Zhang Y, Li YH, Blati M, Fahmi H, Lussier B, Roughley P, Lagares D, Endisha H, Saffar B: Extended report: PPAR $\gamma$ deficiency results in severe, accelerated osteoarthritis associated with aberrant mTOR signalling in the articular cartilage. Ann Rheum Dis 2015;74:569.

-25 Pritzker KP, Gay S, Jimenez SA, Ostergaard K, Pelletier JP, Revell PA, Salter D, Wb VDB: Osteoarthritis cartilage histopathology: grading and staging. Osteoarthritis Cartilage 2006;14:13.

-26 Lewis JS, Hembree WC, Furman BD, Tippets L, Cattel D, Huebner JL, Little D, Defrate LE, Kraus VB, Guilak F: Acute joint pathology and synovial inflammation is associated with increased intra-articular fracture severity in the mouse knee. Osteoarthritis Cartilage 2011;19:864-873.

-27 Smith SR, Deshpande BR, Collins JE, Katz JN, Losina E: Comparative pain reduction of oral non-steroidal anti-inflammatory drugs and opioids for knee osteoarthritis: systematic analytic review. Osteoarthritis Cartilage 2016;24:962-972.

28 Vinatier C, Merceron C, Guicheux J: Osteoarthritis: from pathogenic mechanisms and recent clinical developments to novel prospective therapeutic options. Drug Discov Today 2016;21:1932-1937.

29 Kraan PMVD, Berg WBVD: Chondrocyte hypertrophy and osteoarthritis: role in initiation and progression of cartilage degeneration? Osteoarthritis Cartilage 2012;20:223.

-30 Dreier R: Hypertrophic differentiation of chondrocytes in osteoarthritis: the developmental aspect of degenerative joint disorders. Arthritis Res Ther 2010;12:216.

31 Goldring SR, Goldring MB: The role of cytokines in cartilage matrix degeneration in osteoarthritis. Clin Orthop Relat Res 2004;427:S27.

-32 Li TF, Yukata K, Yin G, Sheu T, Maruyama T, Jonason JH, Hsu W, Zhang X, Xiao G, Konttinen YT: BMP-2 induces ATF4 phosphorylation in chondrocytes through a COX-2/PGE2 dependent signaling pathway. Osteoarthritis Cartilage 2014;22:481-489.

-33 Li N, Rivérabermúdez MA, Zhang M, Tejada J, Glasson SS, Collinsracie LA, Lavallie ER, Wang Y, Chang KC, Nagpal S: LXR modulation blocks prostaglandin E2 production and matrix degradation in cartilage and alleviates pain in a rat osteoarthritis model. Proc Natl Acad Sci U S A 2010;107:3734-3739.

-34 Rasheed N, Alghasham A, Rasheed Z: Lactoferrin fromCamelus dromedariusInhibits Nuclear Transcription Factor-kappa B Activation, Cyclooxygenase-2 Expression and Prostaglandin E2 Production in Stimulated Human Chondrocytes. Pharmacognosy Res 2016;8:135-141.

35 Hardy MM, Seibert K, Manning PT, Currie MG, Woerner BM, Edwards D, Koki A, Tripp CS: Cyclooxygenase 2-dependent prostaglandin E 2 modulates cartilage proteoglycan degradation in human osteoarthritis explants. Arthritis Rheumatol 2002;46:1789-1803.

-36 Zheng W, Zhang H, Jin Y, Wang Q Chen L, Feng Z, Chen H, Wu Y: Butein inhibits IL-1 $\beta$-induced inflammatory response in human osteoarthritis chondrocytes and slows the progression of osteoarthritis in mice. Int Immunopharmacol 2017;42:1-10.

-37 Yang YZ, Tang YZ, Liu YH: Wogonoside displays anti-inflammatory effects through modulating inflammatory mediator expression using RAW264.7 cells. J Ethnopharmacol 2013;148:271. 


\section{Cellular Physiology Cell Physiol Biochem 2018;48:2583-2595 \begin{tabular}{ll|l} 
DOI: 10.1159/000492701 & $\begin{array}{l}\text { O 2018 The Author(s). Published by S. Karger AG, Basel } \\
\text { www.karger.com/cpb }\end{array}$ \\
\hline
\end{tabular} \\ Li et al.: The Protective Effect of Ligustilide in Osteoarthritis}

38 Suh HJ, Lee H, Min BJ, Jung SU, Jung EY: Effects of gangliosides from deer bone extract on the gene expressions of matrix metalloproteinases and collagen type II in interleukin-1ß-induced osteoarthritic chondrocytes. Nutr Res Pract 2016;10:569-574.

-39 Kelwick R, Desanlis I, Wheeler GN, Edwards DR: The ADAMTS (A Disintegrin and Metalloproteinase with Thrombospondin motifs) family. Genome Biol 2015;16:113.

40 Abramson SB, Attur M, Amin AR, Clancy R: Nitric oxide and inflammatory mediators in the perpetuation of osteoarthritis. Curr Rheumatol Rep 2001;3:535.

-41 Li YF, Li SH, Liu Y, Luo YT: Long Noncoding RNA CIR Promotes Chondrocyte Extracellular Matrix Degradation in Osteoarthritis by Acting as a Sponge For Mir-27b. Cell Physiol Biochem 2017;43:602.

42 Oeckinghaus A, Ghosh S: The NF-кB Family of Transcription Factors and Its Regulation. Cold Spring Harb Perspect Biol 2009;1:a000034.

43 Chen WP, Hu ZN, Jin LB, Wu LD: Licochalcone A Inhibits MMPs and ADAMTSs via the NF- $\kappa B$ and Wnt/ $\beta$ Catenin Signaling Pathways in Rat Chondrocytes. Cell Physiol Biochem 2017;43:937-944.

44 Tarantino N, Tinevez JY, Crowell EF, Boisson B, Henriques R, Mhlanga M, Agou F, Israël A, Laplantine E: TNF and IL-1 exhibit distinct ubiquitin requirements for inducing NEMO-IKK supramolecular structures. J Cell Biol 2014;204:231-245. 